\title{
Improving Patient Throughput in a Busy Pediatric Mri Imaging Program Through a Nursing Coordinator
}

\author{
Sanket Shah ${ }^{1 *}$, Martha Carter ${ }^{1}$, Joshua Q Knowlton ${ }^{2}$ \\ From 19th Annual SCMR Scientific Sessions \\ Los Angeles, CA, USA. 27-30 January 2016
}

\section{Background}

Pediatric cardiac MRIs form a small but critical part of MRI imaging at a busy pediatric cardiac imaging center. We had a higher than acceptable rate of no-show and wait times for scheduled cardiac MRIs, which was a source of patient and provider dissatisfaction in our institution. Previously, the process of scheduling a cardiac MRI was facilitated by a nonmedical provider. Dedicated nurse coordinator was added to the Pediatric Cardiac MRI scheduling team to provide a centralized and focused source for referral intakes and coordination of care.

\section{Methods}

The nursing coordinator facilitates scheduling and communication with patients and referring providers. Providers were given a direct phone number and primary fax number to provide ease of referrals and consultations. Patients were given reminder phone calls, emails and letters. During this communication, information about expectations for the MRI visit, directions, overnight accommodation at Ronald McDonald House, transportation resources, NPO instructions were provided as and when necessary.

\section{Results}

Between August 2013 and July 2014, 128 cardiac MRIs were performed by the cardiac imaging center and 11 patients did not report for MRI testing [no-show rate of about 9\%]. Between August 2014 to July, 2015, 169 cardiac MRI have been performed at our hospital with only 6 patients [3.5\%] not showing up for appointment.

${ }^{1}$ Cardiology, CMH, Kansas City, MO, USA

Full list of author information is available at the end of the article

\section{Conclusions}

The addition of a nurse coordinator in a Pediatric Cardiac Imaging Center has resulted in reduced no-show rates. This in turn has resulted in reduced wait times for obtaining a pediatric cardiac MRI and efficient use of resources. A similar scheduling model could be considered where cardiac MRI scanner time and other resources are limited.

\section{Authors' details}

${ }^{1}$ Cardiology, CMH, Kansas City, MO, USA. ${ }^{2}$ Radiology, Children's Mercy Hospital, Kansas City, MO, USA.

Published: 27 January 2016

doi:10.1186/1532-429X-18-S1-P309

Cite this article as: Shah et al:: Improving Patient Throughput in a Busy Pediatric Mri Imaging Program Through a Nursing Coordinator. Journal of Cardiovascular Magnetic Resonance 2016 18(Suppl 1):P309.

Submit your next manuscript to BioMed Central and take full advantage of:

- Convenient online submission

- Thorough peer review

- No space constraints or color figure charges

- Immediate publication on acceptance

- Inclusion in PubMed, CAS, Scopus and Google Scholar

- Research which is freely available for redistribution 